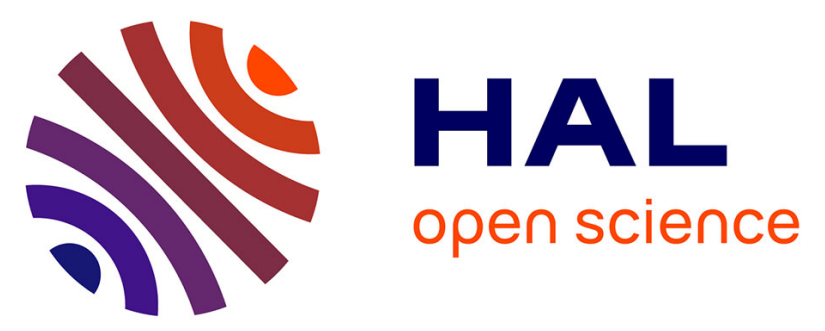

\title{
Investigating the role of SBA-15 silica on the activity of quaternary ammonium halides in the coupling of epoxides and $\mathrm{CO} 2$
}

Florian Lagarde, Hassan Srour, Nicolas Berthet, Nesrine Oueslati, Benjamin Bousquet, Andreia Nunes, Alexandre Martinez, Véronique Dufaud

\section{To cite this version:}

Florian Lagarde, Hassan Srour, Nicolas Berthet, Nesrine Oueslati, Benjamin Bousquet, et al.. Investigating the role of SBA-15 silica on the activity of quaternary ammonium halides in the coupling of epoxides and CO2. Journal of CO2 Utilization, 2019, 34, pp.34-39. 10.1016/j.jcou.2019.05.023 . hal-02397641

\section{HAL Id: hal-02397641 \\ https://hal.science/hal-02397641}

Submitted on 23 Mar 2020

HAL is a multi-disciplinary open access archive for the deposit and dissemination of scientific research documents, whether they are published or not. The documents may come from teaching and research institutions in France or abroad, or from public or private research centers.
L'archive ouverte pluridisciplinaire HAL, est destinée au dépôt et à la diffusion de documents scientifiques de niveau recherche, publiés ou non, émanant des établissements d'enseignement et de recherche français ou étrangers, des laboratoires publics ou privés. 


\title{
Investigating the role of SBA-15 silica on the activity of quaternary ammonium halides in the coupling of epoxides and $\mathrm{CO}_{2}$
}

\author{
Lagarde, F. \\ Srour, $\mathrm{H}$. \\ Berthet, N. \\ Oueslati, N. \\ Bousquet, $B$. \\ Nunes, A. \\ Martinez, A. \\ Dufaud, V.
}

\begin{abstract}
The conversion of $\mathrm{CO}_{2}$ into cyclic carbonates in the presence of epoxides is one of the most promising methods to valorize this important $C_{1}$ building block. Tetrabutylammonium halide salts are known to catalyze this reaction with moderate activity, and often a co-catalyst is added to increase efficiency. Herein, the influence of the addition of ultra-large pore SBA-15 silica on the catalytic activity of tetrabutylammonium halide salts for this reaction has been investigated in detail. Whereas a negative effect of silica was observed for the $\mathrm{NBu}_{4} \mathrm{Cl}$ catalyst, surface silanols were shown to strongly improve the yield of the reaction when $\mathbf{N B u}_{4} \mathbf{B r}$ and $\mathbf{N B u}_{4} \mathrm{I}$ were used as catalysts. The catalytic activity of the $\mathbf{N B u}_{4} \mathbf{I}$ salt could be increased by a factor of ten when a relevant amount of mesoporous silica was added. This latter catalytic system leads to high yields and selectivity for a wide variety of substrates under mild condition $\left(80^{\circ} \mathrm{C}\right)$. Measurement of the activation parameters demonstrated that the rate enhancement is entropically driven: the pre-organization of the reactants and catalyst on the surface leads to a marked decrease of the activation energy of the reaction. A direct comparison between yield improvement induced by the addition of either an amorphous or a mesostructured silica highlights the crucial role played by the shape and concavity of the support.
\end{abstract}

\section{Introduction}

The direct coupling of $\mathrm{CO}_{2}$ and epoxides to produce five-membered cyclic carbonates is an attractive process both from an economic and environmental viewpoint [1]. The use of $\mathrm{CO}_{2}$ as an abundant, nontoxic, and readily available renewable carbon source [2] associated with the high atom efficiency (the degree to which reagents are incorporated into the target products) of this transformation [3] and the diverse applications of carbonate compounds in numerous sectors [4] are among the main reasons accounting for the constant interest of the scientific community for this simple reaction. Over the last decade, a wide variety of metal-based [5] and purely organic [6] homogeneous catalytic systems have been developed to mediate this reaction and overcome the kinetic and thermodynamic stability of $\mathrm{CO}_{2}$, which remains a central challenge in the field of $\mathrm{CO}_{2}$ chemical conversion. Highly active systems able to operate under mild temperature $\left(<100^{\circ} \mathrm{C}\right)$ and pressure (1-10 bar) could be produced by combining a nucleophile (typically a halide anion) with either Lewis acid activators (typically metal based complex) [7a-c] or compounds that can act as Brønsted acid H-bonding donors [7d-1]. The nucleophile and the activator work cooperatively at the epoxide substrate through respectively ring-opening and oxygen atom activation. Although significant progress has been made in terms of catalytic efficiency, several drawbacks associated with homogeneous catalysts (product purification, catalyst recovery, recycling) still need to be addressed before industrial development of this approach. In this regard, one straightforward strategy is to immobilize a known active catalyst onto insoluble carriers through, for example, entrapment, adsorption, ion-pair formation or covalent anchoring: all these methods have been previously well described [8].

Catalytic hybrid materials derived mainly from soluble organocatalysts have recently been applied to the conversion of epoxides with $\mathrm{CO}_{2}$. These include quaternary ammonium and phosphonium salts, ionic liquids, nitrogen-containing bases, and aminopyridinium halides covalently immobilized on supports as varied as carbon nanotubes, organic polymers, chitosan, polyethylene glycol, metal-organic frameworks or inorganic oxides (mainly silica-based oxides) [9]. As 
anticipated, immobilisation not only facilitated catalyst recovery and recycling but, in the case of silica-based supports, there was a further beneficial effect on catalytic performance with respect to soluble counterparts [9b-d]. This reactivity enhancement was attributed to the presence of $\mathrm{Si}-\mathrm{OH}$ groups on the surface of silica, which could act as weakly acidic sites to synergistically activate the epoxide substrate through H-bonding. Thus, the surface silanols mimic the action of the Brønsted acidic activators mentioned above: polyphenols [7d, e], fluorinated alcohols [7f], amino alcohols [7g], and azaphosphatranes [7h-j].

Nevertheless, some questions remain concerning the role played by hydroxylic supports. While the previous reports suggested that the silanols activate the epoxide substrate, some information was lacking concerning the fundamental characteristics of their catalytic action (mass effects, activation parameters, effect on initial rate). We also wished to further explore the comparison of different halides within a given series of experiments, and give attention to the potential interactions between the different halide anions (weak Brønsted bases) with the slightly acidic surface silanols.

In this paper, we report that silanols can have both positive and negative effects on catalysis depending on the nature of the halide counter-anion. Optimisation of the use of added silica can lead to dramatic positive effects, as is demonstrated for the catalytic coupling of styrene oxide with $\mathrm{CO}_{2}$ catalyzed by $\mathbf{N B u}_{4} \mathrm{I}$. We also show that this level of activity makes this particular system viable for use with a broad range of epoxide substrates. The origins of the catalytic effect could be elucidated by the study of the temperature dependence of the reaction, in which entropic factors are shown to predominate. This observation, together with the comparison of the effects of porous and non-porous silicas, lead us to conclusions regarding the preorganization of reactants and catalyst leading to, or at, the transition state of the rate determining step.

\section{Results and Discussion}

Among the different silica supports available, we chose to use a mesoporous silica of the SBA-15 family characterized by ultra-large pore diameters in the range of 9-12 nm (SBA-15 ULP silica) [10]. The increase in pore diameter was achieved by using hexane as swelling agent which can be accommodated inside the hydrophobic micelles at low temperature, thus expanding their volume. In addition to the general properties associated with mesostructured materials (high surface area, well ordered pore arrays, narrow pore size distribution) its large porous volume $\left(1.3 \mathrm{~cm}^{3} \cdot \mathrm{g}^{-1}\right)$ and diameter (91 $\AA$ ) compared to conventional SBA-15 $\left(\sim 1 \mathrm{~cm}^{3} \cdot \mathrm{g}^{-1}\right.$ and $60 \AA$ respectively) provide for greater mass transfer and accessibility to internal surface silanols. The structural and textural properties of native SBA-15 ULP silica have been displayed in Supporting Information (Table S1, Figs. S1 and S2).

The coupling of $\mathrm{CO}_{2}$ and styrene oxide was used as a benchmark reaction to evaluate the influence of SBA-15 ULP silica addition on various tetrabutylammonium halides $\mathbf{N B u}_{4} \mathrm{X}(\mathrm{X}=\mathrm{Cl}, \mathrm{Br}, \mathrm{I})$ reactivity. The reaction was conducted at $80^{\circ} \mathrm{C}$ under 10 bar of $\mathrm{CO}_{2}$ during 18 hours and $2 \mathrm{~mol} \%$ of $\mathbf{N B u}_{4} \mathrm{X}$ catalyst. Methyl 2-butanone (MEK) was used as a reaction solvent to allow, when present, for a good dispersion of the silica support in the reaction medium. Catalytic reactivity of

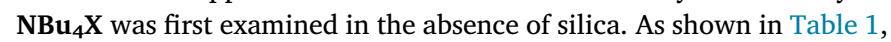
the performance of tetrabutylammonium salts (entries 1-3) is strongly impacted by the nature of the halide anion with a decrease in activity following the order $\mathrm{Br}>\mathrm{Cl}>>$ I. The addition of SBA-15 ULP silica had dramatic and surprising effects. Before examining the effect of the addition of silica to the ammonium salt catalysts, note that the silica by itself has no effect on the reaction (Table 1, entry 4). Added silica produced a strong negative effect on the activity of $\mathrm{NBu}_{4} \mathrm{Cl}$ (compare entries 1 and 5) with a drop of both the yield (from 45 to $28 \%$ ) and the selectivity (from 100 to $62 \%$ ). The effects were very strong and positive for bromide (entries 2 and 6) and especially iodide (entries 3 and 7)
Table 1

Influence of the addition of SBA-15 ULP silica on the coupling of styrene oxide and $\mathrm{CO}_{2}$ catalyzed by tetrabutylammonium halides.

\begin{tabular}{lllll}
\hline Entry & Catalytic system & Conversion (\%) & Yield (\%) & Selectivity (\%) \\
\hline $\mathbf{1}$ & $\mathbf{N B u}_{4} \mathbf{C l}$ & 45 & 45 & 100 \\
$\mathbf{2}$ & $\mathbf{N B u}_{4} \mathbf{B r}$ & 61 & 61 & 100 \\
$\mathbf{3}$ & $\mathbf{N B u}_{\mathbf{I}} \mathbf{I}$ & 12 & 12 & 100 \\
$\mathbf{4}$ & $\mathbf{S B A - 1 5}$ ULP & 0 & 0 & 0 \\
$\mathbf{5}$ & $\mathbf{N B u}_{4} \mathrm{Cl}+\mathbf{S B A}-15$ ULP & 45 & 28 & 62 \\
$\mathbf{6}$ & $\mathbf{N B u}_{4} \mathbf{B r}+\mathbf{S B A - 1 5}$ ULP & 100 & 100 & 100 \\
$\mathbf{7}$ & $\mathbf{N B u}_{4} \mathbf{I}+\mathbf{S B A - 1 5}$ ULP & 100 & 100 & 100 \\
\hline
\end{tabular}

Reaction conditions: Styrene oxide $(2 \mathrm{mmol}), \mathrm{NBu}_{4} \mathrm{X}(2 \mathrm{~mol} \%, \mathrm{X}=\mathrm{Cl}, \mathrm{Br}, \mathrm{I})$, solvent MEK $(6 \mathrm{~mL}), 10 \mathrm{bar}$ of $\mathrm{CO}_{2}, 80^{\circ} \mathrm{C}, 18 \mathrm{~h}$. Where appropriate, $250 \mathrm{mg}$ of native silica (SBA-15 ULP) were introduced prior to the reaction. Yield and conversion were measured by ${ }^{1} \mathrm{H}$ NMR using 2,4-dibromomesitylene $(0.4 \mathrm{mmol})$ as internal standard. Selectivity in cyclic carbonate product is defined as the ratio yield/conversion. The products besides styrene carbonate were identified by GC-MS as styrene glycol and oligo-ethers (up to the tetramere).

ammonium catalysts, both of which led to quantitative conversion and $100 \%$ selectivity to the cyclic carbonate product under these conditions.

To explain the observed activity trend in the presence of silica (entries 5-7), two competing factors should be considered: silica not only promotes the activation of the epoxide substrate (as previously speculated in the literature), but may also affect the reactivity of the halide anion which can participate in hydrogen bonding with surface silanols (a behavior heretofore neglected). The chloride anion is the most basic of the series and so would be more prone to hydrogen bonding, hence significantly lowering its nucleophility. In our case, this negative effect appears to dominate for chloride. Bromide and iodide are extremely weak bases, not susceptible to hydrogen bonding, and so only the positive activation on epoxide was observed. A similar reactivity trend was observed in neat styrene oxide. In the case of $\mathbf{N B u}_{\mathbf{4}} \mathbf{I}$, an increase of the turnover number (TON) from 187 to 331 was achieved in the presence of SBA-15 ULP whereas for the chloride derivative, addition of SBA-15 ULP silica produced a strong negative effect with a drop of the TON from 150 to 46 . Note that the covalent immobilization of the ammonium catalysts onto SBA-15 ULP silica resulted in poor activity [11] highlighting the crucial role of surface silanols concentration on catalytic reactivity.

This reactivity trend was confirmed over a series of reaction times, including much lower levels of conversion. As shown in Fig. 1, bromide

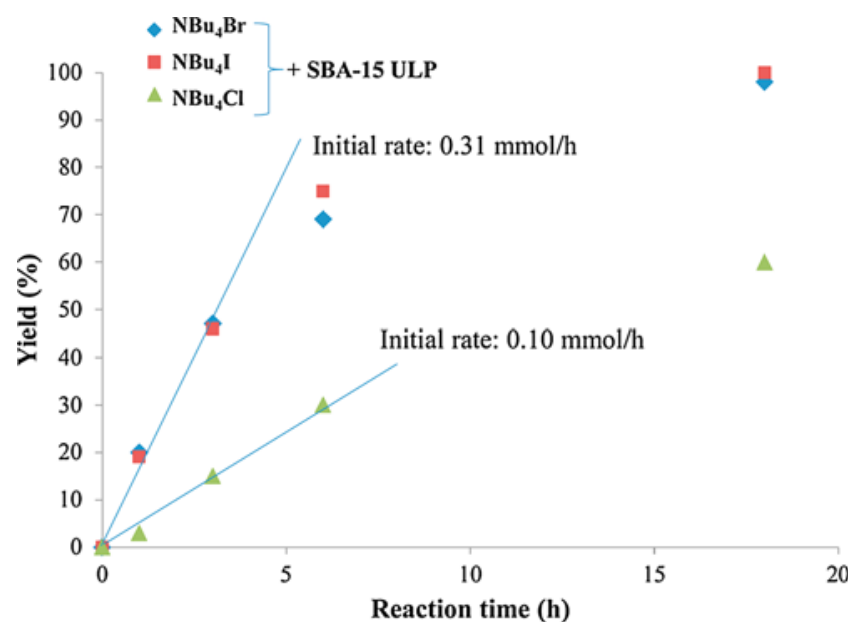

Fig. 1. Kinetic profile of $\mathrm{NBu}_{4} \mathrm{X}$ in the presence of SBA-15 ULP silica. Reaction conditions: Styrene oxide $(2 \mathrm{mmol}), \mathrm{NBu}_{4} \mathrm{X}(2 \mathrm{~mol} \%)$, solvent MEK $(6 \mathrm{~mL})$, mass of SBA-15 ULP silica $(150 \mathrm{mg}), 10 \mathrm{bar}$ of $\mathrm{CO}_{2}, 80^{\circ} \mathrm{C}$. 
and iodide ammonium catalysts exhibited similar activity with yield approaching $70 \%$ after $6 \mathrm{~h}$ of reaction and full conversion at $18 \mathrm{~h}$. The chloride catalyst, on the other hand, showed lower reactivity attaining only $50 \%$ yield after a $18 \mathrm{~h}$ period. The association of both $\mathbf{N B u}_{4} \mathbf{B r}$ and $\mathbf{N B u}_{4} I$ with SBA-15 ULP silica produced very active catalytic systems with initial reaction rates 3-time higher than their chloride counterpart.

Pre-physisorption of the ammonium catalysts onto SBA-15 ULP silica prior to catalysis was also carried out to investigate whether reaction rates could be impacted by diffusional constraints of reactant and catalyst within the pores of silica (see Supporting Information, Fig. S3). Initial rates matched those obtained when both epoxide and ammonium were introduced in solution with $0.35,0.32$ and $0.11 \mathrm{mmol} / \mathrm{h}$ for respectively the iodide, bromide and chloride ammonium salts. This suggests that the reaction is likely occurring at the surface of the silica support and that the diffusion of both epoxide and ammonium catalyst within the pore of mesoporous silica is fast.

Recall that, in the strongest effect observed in this report, added silica led to an order of magnitude enhancement of catalytic activity between the low-active $\mathbf{N B u _ { 4 }} \mathbf{I}$ system ( $12 \%$ yield), and the $\left\{\mathbf{N B u}_{4} \mathbf{I}+\right.$ SBA-15 ULP silica\} system (100\% yield). Given this remarkable improvement, we choose to pursue our catalytic studies with this catalyst/ co-catalyst couple in order to elucidate the impact of silanols on halide activity and epoxide activation.

In order to investigate more accurately this influence, the time dependent profile of $\mathrm{NBu}_{4} \mathrm{I}$ in the presence and absence of SBA-15 ULP silica was determined (Fig. 2). The initial rate was indeed approximately ten times higher in the presence of SBA-15 ULP silica over a significant range of time and conversion, highlighting its remarkable capability to enhance the activity of $\mathbf{N B u}_{4} \mathbf{I}$ even at short reaction time.

The polarity of the surface of SBA-15 ULP silica was characterized by $\mathrm{BET}$, and the measured $\mathrm{C}_{\mathrm{BET}}$ value of 146 issued from the nitrogen sorption experiments (Table S1, Supporting Information) indicates a high density of surface silanols and hydrophilic character which could explain the activity improvement observed. The effect of the quantity of silica added on $\mathrm{NBu}_{4} \mathrm{I}$ reactivity was also evaluated. As shown in Fig. 3 (data available in Supporting Information, Table S3), in the absence of silica, the reaction proceeds with very low activity, leading to only $10 \%$ yield of styrene carbonate after 6 hours. Increasing the mass of silica added from 50 to $150 \mathrm{mg}$ led to steadily increasing the yield from 45 to $75 \%$, after which a falling off of the yield was observed while further increasing the mass of silica to $450 \mathrm{mg}$.

One should consider that increasing the mass of added silica implies the increase of the total surface area available for interaction with both the epoxide substrate and the halide catalyst. Given that substrate and catalyst amounts are constant over this series, one should also consider

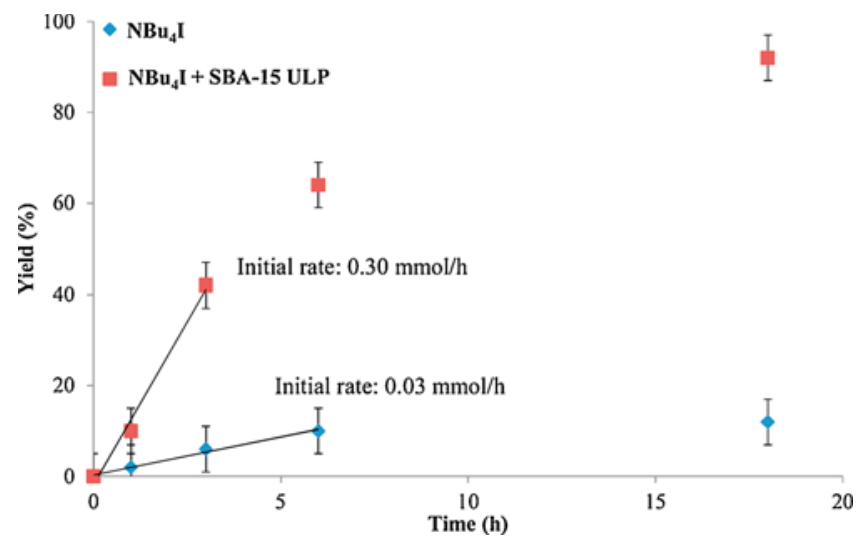

Fig. 2. Kinetic profile of $\mathrm{NBu}_{4} \mathrm{I}$ in the presence and absence of SBA-15 ULP silica.

Reaction conditions: Styrene oxide ( $2 \mathrm{mmol}), \mathrm{NBu}_{4} \mathrm{I}(2 \mathrm{~mol} \%)$, solvent MEK $(6 \mathrm{~mL}), 10 \mathrm{bar}$ of $\mathrm{CO}_{2}, 80^{\circ} \mathrm{C}$. Where appropriate, $250 \mathrm{mg}$ of native silica (SBA15 ULP) were introduced prior to the reaction

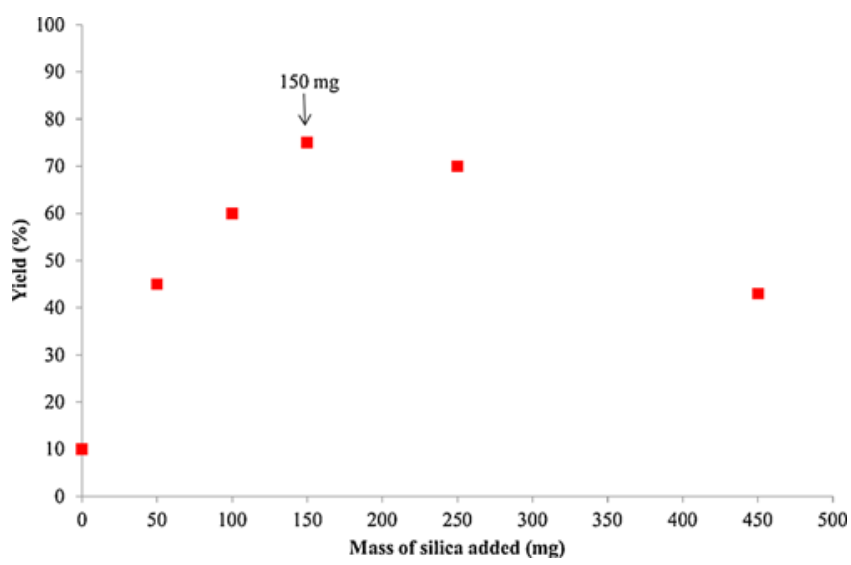

Fig. 3. Effect of the mass of SBA-15 ULP silica added on $\mathrm{NBu}_{4} \mathrm{I}$ catalytic reactivity.

Reaction conditions: Styrene oxide ( $2 \mathrm{mmol}), \mathrm{NBu}_{4} \mathrm{I}(2 \mathrm{~mol} \%)$, solvent MEK $(6 \mathrm{~mL})$, mass of SBA-15 ULP silica $(50-450 \mathrm{mg}), 10$ bar of $\mathrm{CO}_{2}, 80^{\circ} \mathrm{C}, 6 \mathrm{~h}$.

that increasing mass (and thus surface area and the stoichiometric amount of silanols) means lower overall ammonium halide/silanol and epoxide/silanol ratios in the reaction medium. At high ratios (little silica added), the catalyst and substrate are in competition for surface silanol interactions: when the mass of silica added is low, most of the surface silanols would be masked by the polar ammonium halide catalyst presumably making activation of the epoxide, which is the key to the catalytic enhancement, much more difficult. Increasing the amount of silica would lead to a decrease of the ammonium coverage allowing for a better cooperative action of the iodide anion and the Si-OH group at the epoxide substrate. Addition of larger amount of silica could result in stronger iodide anion trapping through hydrogen bonding leading to lower activity. This would explain that the beneficial effect of added silica on activity passes through a maximum, in this series at $150 \mathrm{mg}$. Note that the selectivity was not significantly affected by the mass of silica added.

The effect of the reaction temperature on the catalytic performance of $\mathbf{N B u}_{4} \mathbf{I}$ was then explored in the presence and absence of SBA-15 ULP silica to get deeper insight into the role played by the silica on the reaction kinetics. Fig. 4 revealed that in the presence of silica the reactivity of $\mathbf{N B u}_{4} \mathbf{I}$ was strongly affected by the variation of reaction temperature whereas when used alone this effect was less pronounced. Under homogeneous conditions, $\mathbf{N B u}_{4} \mathbf{I}$ showed no activity at

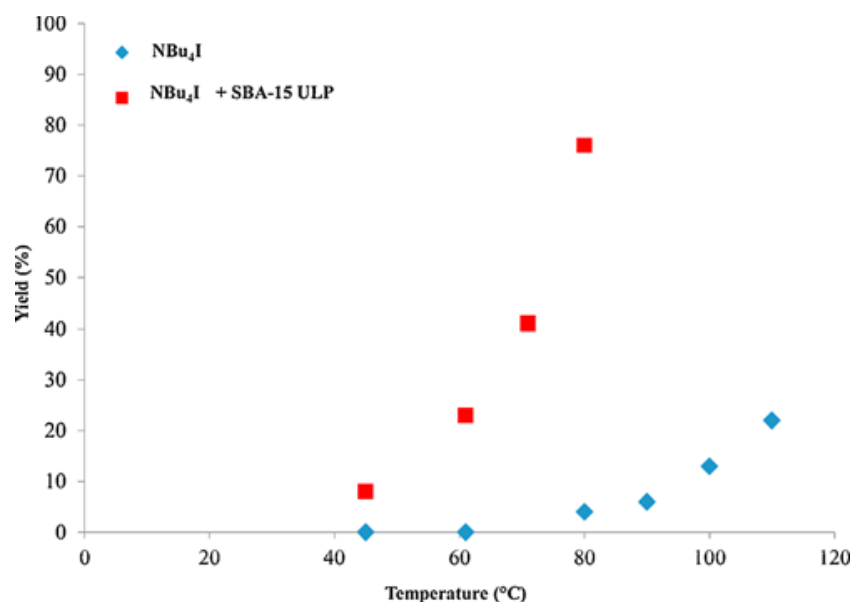

Fig. 4. Influence of reaction temperature on the yield of styrene carbonate catalyzed by $\mathrm{NBu}_{4} \mathrm{I}$ in the presence and absence of SBA-15 ULP silica. Reaction conditions: Styrene oxide $(2 \mathrm{mmol}), \mathrm{NBu}_{4} \mathrm{I}(2 \mathrm{~mol} \%)$, solvent MEK ( $6 \mathrm{~mL})$, mass of SBA-15 ULP silica $(150 \mathrm{mg}), 10$ bar of $\mathrm{CO}_{2}, 6 \mathrm{~h}$. 
temperature below $60^{\circ} \mathrm{C}$ and the increase of temperature to $110^{\circ} \mathrm{C}$ only led to a slight improvement of the yield with a value around $20 \%$. In the presence of silica, however, noticeable activity was already shown at $45^{\circ} \mathrm{C}$ which rapidly increased while raising the temperature. At $80^{\circ} \mathrm{C}$, a yield of $76 \%$ could be achieved in $6 \mathrm{~h}$ against $4 \%$ without silica highlighting the crucial role of silica in reducing the kinetic barriers.

The Gibbs energy of activation for the formation of styrene carbonate derived from the kinetic data at variable temperature could be obtained from the Eyring-Polanyi equation giving rise to the determination of the enthalpy and entropy of activation for both catalytic systems (Fig. S4, Supporting Information). For the reaction catalyzed by $\mathrm{NBu}_{4} \mathrm{I}$ alone, the enthalpy $\left(\Delta \mathrm{H}^{\#}\right)$ and entropy $\left(\Delta \mathrm{S}^{\#}\right)$ of activation were found to be respectively $65 \mathrm{~kJ} \mathrm{~mol}^{-1}$ and $-172 \mathrm{JK}^{-1} \mathrm{~mol}^{-1}$ against $71 \mathrm{~kJ} \mathrm{~mol}^{-1}$ and $-125 \mathrm{JK}^{-1} \mathrm{~mol}^{-1}$ when silica was present. The slight increase of the enthalpy of activation in the presence of silica could be explained by the presence of additional hydrogen bonding, for example between the surface silanols and the epoxide, which would stabilize the initial state. In a similar fashion, these weak bonds would reduce the entropy of the reactants (pre-organization) in the presence of silica, which would be expected to reduce the absolute value of the entropy of activation, which was indeed observed $\left(\Delta \Delta \mathrm{S}^{\#}\right.$ of $\left.47 \mathrm{JK}^{-1} \mathrm{~mol}^{-1}\right)$. Thus, it appears that the entropic parameter, the pre-organization of reactants and catalyst at the surface, is key to improving the reactivity of the catalytic system, and the use of the nanostructured SBA-15 ULP silica may increase the effect via cage phenomena due to the presence of mesopores.

To test this hypothesis, we did a comparative study using SBA-15 ULP silica and an amorphous fumed silica (Degussa) which presents a non-porous surface. In Table 2, we have taken the optimal test from the mass added study described above, that is a run in which $150 \mathrm{mg}$ of SBA-15 ULP were added. Two comparative runs are proposed in Table 2, the first in which we have introduced the same mass of silica (entry 2) and the other in which we have added a quantity of nonporous silica such that we have added the same silica surface area as that of the SBA-15 ULP silica ( $84 \mathrm{~m}^{2}$ corresponding to $418 \mathrm{mg}$, entry 3 ). The latter produces a similar number of surface silanols available (4.6 $4.9 \mathrm{OH} . \mathrm{nm}^{-2}$ ) for interaction with reactants and/or the ammonium catalyst as estimated by Zhuravlev's model [12]. In no case was the non-porous silica sufficient to match the catalytic enhancement of the SBA-15 ULP silica. Yields were reduced and selectivity either unaffected (for low yield, entry 2), or significantly degraded (entry 3). Clearly, the mesostructured silica presents an advantage not provided by non-porous silica, even when the total silica surface area (and number of silanols) is unchanged. The exact nature of these positive effects is difficult to determine. Perhaps they are due to the regular concave curved morphology of the surface which might provide a favorable geometry for the cooperative interactions of silanols, halide and epoxide. Confinement of the reagents may also lead to favoring the proximity of reactants.

The effect of silica addition on the reactivity of $\mathbf{N B u}_{4} I$ catalyst was further investigated using various terminal and internal epoxides to assess the generality of the reactivity promotion observed with styrene oxide. For comparison purpose, catalytic runs with $\mathbf{N B u}_{4} \mathrm{I}$ alone were also conducted for each of the epoxides. As observed from Table 3, the beneficial effect of SBA-15 ULP silica was clearly demonstrated for
Table 3

Substrate scope in the coupling of $\mathrm{CO}_{2}$ with various terminal and internal epoxides catalyzed by $\left\{\mathrm{NBu}_{4} \mathrm{I}+\right.$ SBA-15 ULP $\}$ binary system.

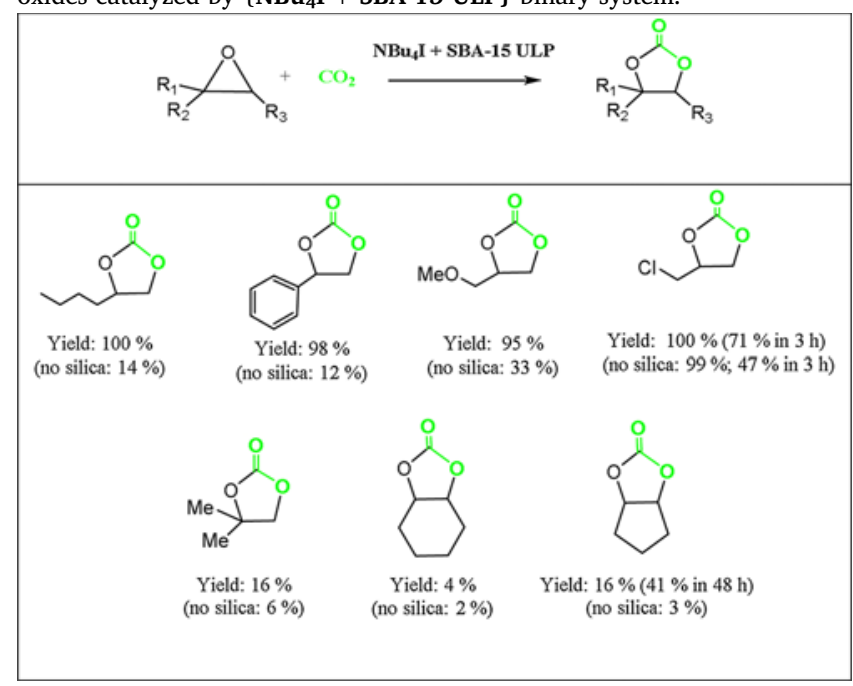

Reaction conditions: Epoxide ( $2 \mathrm{mmol}), \mathrm{NBu}_{4} \mathrm{I}(2 \mathrm{~mol} \%)$, solvent MEK $(6 \mathrm{~mL})$, mass of SBA- 15 ULP silica $(150 \mathrm{mg}), 10 \mathrm{bar}$ of $\mathrm{CO}_{2}, 80^{\circ} \mathrm{C}, 18 \mathrm{~h}$. The selectivity in the cyclic carbonate product was $100 \%$ for each of the reaction.

almost all the cases studied. For mono-substituted terminal epoxides (namely 1,2-epoxyhexane, styrene oxide and glycidyl methtyl ether), yields were improved by a factor varying between 2.8 to 8 in the presence of SBA-15 ULP silica with the exception of epichlorohydrin. In the case of this very reactive epoxide, enhancement of the reactivity (up to $51 \%$ ) was measurable only by reducing the reaction time to $3 \mathrm{~h}$. In the case of the more challenging di-substituted terminal 1,2-epoxy-2methylpropane and for the sterically hindered cyclopentene and cyclohexene oxides, improvement of the activity was indeed observed when silica was present but the overall activity remains low (2 to $6 \%$ without SBA-15 ULP silica, 4 to $16 \%$ with SBA-15 ULP silica). Increasing the reaction time to $48 \mathrm{~h}$ allowed, however, achieving in the case of cyclopentene oxide further conversion improvement with $41 \%$ yield of the corresponding carbonate.

\section{Conclusion}

We have shown that the addition of silica significantly impacts the catalytic performance of tetrabutylammonium halide salts. When the effect is positive ( $\mathrm{NBu}_{4} \mathrm{Br}$ and $\left.\mathbf{N B u}_{4} \mathrm{I}\right)$, surface silanols are thought to be the principal agent for these effects via activation of the epoxide substrate by hydrogen bonding to the epoxide oxygen. In the case of $\mathrm{NBu}_{4} \mathrm{Cl}$, silanols have shown the potential to have a deleterious effect on catalysis which is also attributed to hydrogen bonding, in this case, through trapping the chloride nucleophile which needs to intervene in the key catalytic step, the ring-opening of the epoxide. A similar negative effect was also observed for $\mathbf{N B u}_{4} \mathbf{I}$ when there was an excess of surface silanols. Activation parameters were determined and showed that entropic effects are very significant, implying that the added silica

Table 2

Effect of the confinement on the reactivity of tetrabutylammonium iodide in the coupling of styrene oxide and $\mathrm{CO}_{2}$.

\begin{tabular}{|c|c|c|c|c|c|c|}
\hline Entry & Catalytic system & $\begin{array}{l}\text { Mass of silica added } \\
(\mathrm{mg})\end{array}$ & $\begin{array}{l}\text { Surface area added } \\
\left(\mathrm{m}^{2}\right)\end{array}$ & Conversion (\%) & Yield (\%) & Selectivity (\%) \\
\hline 1 & $\mathrm{NBu}_{4} \mathrm{I}+\mathrm{SBA}-15$ ULP & 150 & 84 & 75 & 76 & 100 \\
\hline 2 & $\mathrm{NBu}_{4} \mathrm{I}+\mathrm{SiO}_{2}$ & 150 & 30 & 28 & 27 & 100 \\
\hline 3 & $\mathrm{NBu}_{4} \mathrm{I}+\mathrm{SiO}_{2}$ & 418 & 84 & 60 & 56 & 93 \\
\hline
\end{tabular}

Reaction conditions: Styrene oxide ( $2 \mathrm{mmol}), \mathrm{NBu}_{4} \mathrm{I}(2 \mathrm{~mol} \%)$, solvent MEK $(6 \mathrm{~mL}), 10$ bar of $\mathrm{CO}_{2}, 80^{\circ} \mathrm{C}, 6 \mathrm{~h}$. Specific surface area $\left(\mathrm{S}_{\mathrm{BET}}\right): 201 \mathrm{~m}^{2} / \mathrm{g}_{\text {for SiO}}, 561 \mathrm{~m}^{2} / \mathrm{g}$ for SBA-15 ULP. 
plays a role in the preorganization of substrate and catalyst leading to, or at, the transition state of the rate determining step. Differences between amorphous silica and a mesostructured silica were significant, implying that morphological factors such as surface regularity or concavity may be in play. The beneficial effect of silica has been demonstrated for the $\mathbf{N B u}_{4} \mathbf{I}$ catalyst for a large scope of epoxide substrates including low-reactive disubstituted epoxides.

\section{Experimental Section}

\subsection{General}

Commercial reagents were purchased from Aldrich Chemical and Alfa-Aesar and used without further purification unless otherwise noted. Aerosil silica $\left(201 \mathrm{~m}^{2} / \mathrm{g}\right)$ was purchased from Degussa and activated at $200{ }^{\circ} \mathrm{C}$ before use. $\mathrm{CO}_{2}$ of a purity of $99.99 \%$ was commercially obtained and used without further purification. Small-angle X-ray powder diffraction (XRD) data were acquired on a Bruker D5005 diffractometer using $\mathrm{Cu} \mathrm{K \alpha}$ monochromatic radiation $(\lambda=1.5418 \AA)$. Nitrogen adsorption-desorption isotherms at $77 \mathrm{~K}$ were measured using a Micromeritics ASAP $2020 \mathrm{M}$ physisorption analyzer. The samples were evacuated at $10^{-5}$ torr and $150{ }^{\circ} \mathrm{C}$ during $15 \mathrm{~h}$ before the measurements. Specific surface areas were calculated following the BET procedure. Pore size distribution was obtained by using the BJH pore analysis applied to the desorption branch of the nitrogen adsorption-desorption isotherm.

\subsection{Synthesis of SBA-15 ULP silica}

The synthesis of SBA-15 ultra-large pore (SBA-15 ULP) mesoporous material is based on the procedure described by Sun et al. [10]. Typically, Pluronic P123 (10.1 g) was dissolved in a mixture of $\mathrm{HCl} 37 \%$ ( $37.6 \mathrm{~mL}$ ) and $\mathrm{H}_{2} \mathrm{O}(313.2 \mathrm{~mL}$ ) at room temperature followed by the addition of $\mathrm{NH}_{4} \mathrm{~F}(0.11 \mathrm{~g})$. The solution was cooled down to $15^{\circ} \mathrm{C}$ and stirred for $1 \mathrm{~h}$. A pre-mixed solution composed of TEOS $(21.3 \mathrm{~g})$ and hexane $(35.4 \mathrm{~g}$ ) was added drop wise and the solution was stirred for an additional $20 \mathrm{~h}$ at $15{ }^{\circ} \mathrm{C}$ obtaining a gel with a composition of 1 TEOS : $0.017 \mathrm{P} 123: 0.4$ hexane : $0.03 \mathrm{NH}_{4} \mathrm{~F}: 4.4 \mathrm{HCl}: 184 \mathrm{H}_{2} \mathrm{O}$. The mixture was then aged for $48 \mathrm{~h}$ at $100{ }^{\circ} \mathrm{C}$. The resulting solid product was filtered, washed with distilled water $(250 \mathrm{~mL})$ and dried at $60^{\circ} \mathrm{C}$ overnight. Finally, the solid was calcined under flowing air at $540^{\circ} \mathrm{C}$ for $4 \mathrm{~h}$, with a heating rate of $2{ }^{\circ} \mathrm{C} / \mathrm{min}$. The conversion, yield and selectivity are defined as follows: conversion of substrate $(\%)=[($ moles of epoxide added - moles of epoxide remained)/moles of epoxide added] $\mathrm{x}$ 100 ; yield of product $(\%)=$ [moles of cyclic carbonate/moles of epoxide added] x 100; Selectivity in cyclic carbonate product is defined as the ratio yield/conversion.

\subsection{Catalytic procedure}

In a typical experiment, styrene oxide ( $2 \mathrm{mmol}), \mathrm{NBu}_{4} \mathrm{X}(\mathrm{X}=\mathrm{Cl}, \mathrm{Br}$, I, $2 \mathrm{~mol} \%$ ), MEK $(6 \mathrm{~mL})$ and 2,4-dibromomesitylene $(0.4 \mathrm{mmol}$, used as internal standard) were loaded into a $25 \mathrm{~mL}$ stainless autoclave. The reactor was flushed three times at room temperature with 5 bar of $\mathrm{CO}_{2}$ to remove air from the vessel before being further charged to $10 \mathrm{bar}$ of $\mathrm{CO}_{2}$ and raised to $80^{\circ} \mathrm{C}$. After the desired reaction time, the reactor was cooled with an ice bath to stop the reaction and finally the excess of $\mathrm{CO}_{2}$ was carefully released. The crude mixture was analyzed by ${ }^{1} \mathrm{H}$ NMR. When silica was added (50 - $450 \mathrm{mg}$ ), the solid was thoroughly washed with acetonitrile $(3 \mathrm{~mL})$ and recovered by centrifugation. This procedure was repeated until the ${ }^{1} \mathrm{H}$ NMR didn't show any residual peaks. Finally, the different fractions were collected and analyzed by ${ }^{1} \mathrm{H}$ NMR as in a classical experiment.

[1] (a) M. Aresta, Carbon Dioxide as Chemical Feedstock, Wiley-VCH, Weinheim, 2010;

(b) I. Omae, Catal. Today 115 (2006) 33-52;

(c) T. Sakakura, J.-C. Choi, H. Yasuda, Chem. Rev. 107 (2007) 2365-2387.

[2] (a) J.A. Martens, A. Bogaerts, N. De Kimpe, P.A. Jacobs, G.B. Marin, K. Rabaey, M. Saeys, S. Verhelst, ChemSusChem 10 (2017) 1039-1055;

(b) Q.-W. Song, Z.-H. Zhou, L.-N. He, Green Chem. 19 (2017) 3707-3728;

(c) A.W. Kleij, M. North, A. Urakawa, ChemSusChem 10 (2017) 1036-1038;

(d) Q. Liu, L. Wu, R. Jackstell, M. Beller, Nat. Commun. 6 (2015) 5933, https://doi. org/10.1038/ncomms6933;

(e) C. Maeda, Y. Miyazaki, T. Ema, Catal. Sci. Technol. 4 (2014) 1482-1497.

[3] (a) M. North, R. Pasquale, C. Young, Green Chem. 12 (2010) 1514-1539;

(b) P. Pescarmona, M. Taherimehr, Catal. Sci. Technol. 2 (2012) 2169-2187; (c) C.J. Whiteoak, A. Nova, F. Maseras, A.W. Kleij, ChemSusChem 5 (2012) 2032-2038;

(d) H. Büttner, L. Longwitz, J. Steinbauer, C. Wulf, T. Werner, Top. Curr. Chem. 375 (2017) 1-56;

(e) C. Martín, G. Fiorani, A.W. Kleij, ACS Catal. 5 (2015) 1353-1370.

[4] (a) D.J. Darensbourg, Chem. Rev. 107 (2007) 2388-2410;

(b) J.H. Clements, Ind. Eng. Chem. Res. 42 (2003) 663-674;

(c) B. Schäffner, F. Schäffner, S.P. Verevkin, A. Börner, Chem. Rev. 110 (2010) 4554-4581;

(d) A.-A.G. Shaikh, S. Sivaram, Chem. Rev. 96 (1996) 951-976.

[5] (a) J. Meléndez, M. North, R. Pasquale, Eur. J. Inorg. Chem. (2007) 3323-3326; (b) C.J. Whiteoak, N. Kielland, V. Laserna, F. Castro-Gómez, E. Martin, E.C. Escuardo-Adán, C. Bo, A.W. Kleij, Chem. Eur. J. 20 (2014) 2264-2275;

(c) T. Ema, Y. Miyazaki, S. Koyama, Y. Yano, T. Sakai, Chem. Commun. 48 (2012) 4489-4491;

(d) C. Martín, C.J. Whiteoak, E. Martin, M. Martínez, E.C. Belmonte, A. EscuderoAdán, W. Kleij, Catal. Sci. Technol. 14 (2014) 1615-1621;

(e) J.A. Castro-Osma, K.J. Lamb, M. North, ACS Catal. 6 (2016) 5012-5025;

(f) J.W. Comerford, I.D. Ingram, M. North, X. Wu, Green Chem. 17 (2015) 1966-1987.

[6] (a) V. Calo, A. Nacci, A. Monopoli, A. Fanizzi, Org. Lett. 4 (2002) 2561-2563; (b) Z.-Z. Yang, L.-N. He, C.-X. Miao, S. Chanfreau, Adv. Synth. Catal. 352 (2010) 2233-2240;

(c) E.R. Pérez, M. Odnicki da Silva, V.C. Costa, U.P. Rodrigues-Filho, D.W. Franco, Tetrahedron Lett. 43 (2002) 4091-4093;

(d) Y. Tsutsumi, K. Yamakawa, M. Yoshida, T. Ema, T. Sakai, Org. Lett. 12 (2010) 5728-5731;

(e) Y.-M. Shen, W.-L. Duan, M. Shi, Adv. Catal. 345 (2003) 337-340;

(f) G. Fiorani, W. Guo, A.W. Kleij, Green Chem. 17 (2015) 1375-1389;

(g) M. Alves, B. Grignard, R. Mereau, C. Jerome, T. Tassaing, C. Detrembleur, Catal. Sci. Technol. 7 (2017) 2651-2684.

[7] (a) J. Rintjema, A.W. Kleij, ChemSusChem 10 (2017) 1274-1282;

(b) A. Decortes, A.M. Castilla, A.W. Kleij, Angew. Chem. Int. Ed. 49 (2010) 9822-9837;

(c) S. Dagorne, R. Wehmschulte, ChemCatChem 10 (2018) 2509-2520; (d) C.J. Whiteoak, A. Nova, F. Maseras, A.W. Kleij, ChemSusChem 5 (2012) 2032-2038;

(e) L. Martinez-Rodriguez, J. Otalora garmilla, A.W. Kleij, ChemSusChem 9 (2016) 749-755;

(f) S. Gennen, M. Alves, R. Mereau, T. Tassaing, B. Gilbert, C. Detrembleur,

C. Jerome, B. Grignard, ChemSusChem 8 (2015) 1845-1849;

(g) T. Werner, N. Tenhumberg, J. $\mathrm{CO}_{2}$ Util. 7 (2014) 39-45;

(h) B. Chatelet, L. Joucla, J.-P. Dutasta, A. Martinez, K.C. Szeto, V. Dufaud, J. Am. Chem. Soc. 135 (2013) 5348-5351;

(i) B. Chatelet, E. Jeanneau, J.-P. Dutasta, V. Robert, A. Martinez, V. Dufaud, Catal. Commun. 52 (2014) 26-30;

(j) B. Chatelet, L. Joucla, J.-P. Dutasta, A. Martinez, V. Dufaud, Chem. Eur. J. 20 (2014) 8571-8574;

(k) N. Liu, Y.-F. Xie, C. Wang, S.-J. Li, D. Wei, M. Li, B. Dai, ACS Catal. 8 (2018) 9945-9957;

(1) P. Yingcharoen, C. Kongtes, S. Arayachukiat, K. Suvarnapunya,

S.V.C. Vummaleti, S. Wannakao, L. Cavallo, A. Poater, V. D' Eliaa, Adv. Synth. 
Catal. 361 (2019) 366-373.

[8] P. McMorn, G.J. Hutchings, Chem. Soc. Rev. 33 (1972) 108-122.

[9] (a) R.A. Watile, K.M. Deshmukh, K.P. Dhake, B.M. Bhanage, Catal. Sci. Technol. 2 (2012) 1051-1055;

(b) K. Motokura, S. Itagaki, Y. Iwasawa, A. Miyaji, T. Baba, Green Chem. 11 (2009) 1876-1880;

(c) T. Sakai, Y. Tsutsumi, T. Ema, Green Chem. 10 (2008) 337-341;

(d) T. Takahashi, T. Watahiki, S. Kitazume, H. Yasuda, T. Sakakura, Chem. Comm. (2006) 1664-1666;

(e) Y. Zhao, J.-S. Tian, X.-H. Qi, Z.-N. Han, Y.-Y. Zhuang, L.-N. He, J. Mol. Catal. A: Chemical 271 (2007) 284-289;

(f) Y. Du, J.-Q. Wang, J.-Y. Chen, F. Cai, J.-S. Tian, D.-L. Kong, L.-N. He, Tetrahedron Lett. 47 (2006) 1271-1275;

(g) S. Baj, T. Krawczyk, K. Jsiak, A. Siewniak, M. Pawlyta, Appl. Catal. A 488 (2014) 96-102;

(h) C. Kohrt, T. Werner, ChemSusChem 8 (2015) 2031-2034;

(i) J. Steinbauer, L. Longwitz, M. Frank, J. Epping, U. Kragl, T. Werner, Green Chem. 19 (2017) 4435-4445;

(j) W.-G. Cui, G.-Y. Zhang, T.-L. Hu, X.-H. Bu, Coord. Chem. Rev. 387 (2019) 79-120; (k) R.R. Shaikh, S. Pornpraprom, V. D'Elia, ACS Catal. 8 (2018) 419-450;

(l) K. Huang, J.-Y. Zhang, F. Liu, S. Dai, ACS Catal. 8 (2018) 9079-9102.

[10] J. Sun, H. Zhang, D. Ma, Y. Chen, X. Bao, A. Klein-Hoffmann, N. Pfänder, D. sheng Su, Chem. Commun. (2005) 5343-5345.

[11] Previous literature studies have concerned mainly covalently immobilization of the halide ammonium salts. For comparative purpose, we prepared a series of such materials by grafting $\mathrm{N}$-[3-(trimethoxysilyl)propyl]-N,N,N-tributylammonium chloride on the surface of SBA-15 ULP silica followed by anion exchange with $\mathrm{NaBr}$ and NaI to afford respectively the bromide and iodide derivatives. These catalysts had poor activity and of no essential interest to the study presented in this report, but the catalytic results have been included in Supporting Information (Table S2).

[12] In our experiments, both SBA-15 ULP and $\mathrm{SiO}_{2}$ silicas have been activated at $190^{\circ} \mathrm{C}$ under vacuum prior to catalysis. At this pretreatment temperature, only physically adsorbed water has been removed leaving a silica surface fully hydroxylated. As demonstrated by Zhuravlev's model, the magnitude of the silanols number is independent of the origin and structural characteristics of amorphous silica and is considered to be a physico-chemical constant known as the Kiselev-Zhuravlev constant with a numerical value of $4.6-4.9 \mathrm{OH}_{\mathrm{nm}}{ }^{-2}$. For further discussion of the concentration of silanols in this type of silica see L.T. Zhuravev Colloids and Surfaces A: Physicochem. Eng. Aspects 173 (2000) 1-38. 